matology evolved to become a source of data and information for specific themes, such as drought and abrupt climate change PANGAEA" has "special emphasis on environmental, marine and geological basic research", with the potent notion of being an exemplary publication and library system for scientific, geo-referenced data. Whether you prefer the one or the other World Data Centre may depend on your personal needs, or your fondness for (1) more focused data collections (WDCPaleoclimatology), or (2) data mining in a billion data points warehouse (PANGAEA ${ }^{\otimes} /$ WDC-MARE).

To realize the digital library-of-data concept, data sets are perceived as data entities. A data entity consists of metainformation and data. Meta-information is any information describing a data set. Data is the pure, primary scientific information, which can be numbers, text, graphics, logging, audio and video recording and reproduction, etc. Where a dendrochronological record provides a few bytes of data only, CTD profiles can deliver some kilobytes of data, and satellite information measure beyond the megabyte border. Whether a single data point is recorded or a gigabyte mass data stream, it is not size that matters. It is rather the data set's scientific value and its unconfined availability (cf., panFMP, Schindler and Diepenbroek, 2008), and the standard assignment of one unique persistent, bibliographic identifier per data set to turn a plain data set into an autonomous data publication, cross-referenced with its original scientific paper. Data archiving is carried out in close coordination with the principal investigator. Owing to networking with other systems, database contents can be tracked down by means of search engines, portals, and online library catalogs. The technique of data citation gives a strong motivation for scientists to publish their data, which in the long range will improve data quality and availability.

Some data publications relate to individual papers or studies, while others are vast compilations and syntheses that receive periodic updates. For example, the Climatological Database for the World's Oceans (CLIWOC; Gallego et al., 2005) with climatological and meteorological observations from ship logbooks between 1750 and 1854, contains some 5000 data sets. Based on 36 original scientific papers, Anderson and Mulitza (2001) compiled a 7791 digit set of $\delta^{18} \mathrm{O}$ data from planktic foraminifers in surface sediments. As part of the Paleoclimate Database of the Quaternary (PKDB), Frenzel et al. (2001) document the atlas of paleoclimates and paleoenvironments of the northern hemisphere. The International Tree Ring Databank is continually updated, and provides the field with not only ten thousand raw ring-width measurements but also stan- dardized chronologies and data quality statistics. Some data publications are remarkable for their unusual content. Müller et al. (2005) have archived harmonic tremor signals of the so-called "singing iceberg".

Paleo data give us the window on the past. Beyond their presentation in individual publications, paleo data form a rich tapestry of the four-dimensions we inhabit (time, latitude, longitude, and elevation). They tell us when, for how long, and for what reasons, the climate has changed. Digital data libraries make it all possible.

\section{References}

Anderson, D.M. and Mulitza, S., 2001: Compilation of delta ${ }^{18} 0$ data from planktonic foraminifera in surface sediment, Publishing Network for Geoscientific and Environmental Data, doi: 10.1594/ PANGAEA.60896.

Berlin Declaration on Open Access to Knowledge in the Sciences and Humanities, 2003: Berlin, 4.

Müller, C., Schlindwein, V., Eckstaller, A. and Miller, H., 2005: Audio record of the 'singing iceberg' from the Weddell Sea, Antarctica, Publishing Network for Geoscientific and Environmental Data, doi: 10.1594/PANGAEA.339110

Organisation for Economic Co-operation and Development, OECD, 2007 : Principles and Guidelines for Access to Research Data from Public Funding, OECD Publishing, Paris, 24.

Schindler, U. and Diepenbroek, M., in press: Generic framework for metadata portals, Computer and Geosciences.

For full references please consult:

www.pages-igbp.org/products/newsletter/ref2008_2.html

\title{
PMIP (Paleoclimate Modelling Intercomparison Project)
}

\section{Pascale Braconnot ${ }^{1}$ and Sandy P. Harrison ${ }^{2}$}

${ }^{1}$ Laboratory for Climate and Environment Sciences, Gif-sur-Yvette, France; pascale.braconnot@lsce.ipsl.fr

2School of Geographical Sciences, University of Bristol, UK; sandy.harrison@bristol.ac.uk

The Paleoclimate Modelling Intercomparison Project (PMIP) is a long-standing initiative endorsed by both the WCRP/CLIVAR (World Climate Research Programme/ Climate Variability and Predictability) Working Group on Coupled Modelling (WGCM) and PAGES. It has provided an efficient mechanism for coordinating paleoclimate modeling activities, which provide valuable information on the mechanisms of climate change, the identification of key feedbacks operating in the climate system, and the capability of climate models to reproduce climates different from today. Thanks to the production of data syntheses and to rigorous modeldata comparisons, the mid-Holocene (ca. 6 kyr BP) and the Last Glacial Maximum (LGM; ca. 21 kyr BP) are now recognized as benchmark periods for climate models. Although the main focus is on model-model intercomparison and evaluation, PMIP has acted as an important discussion forum, promoting the understanding of past climate changes as a necessary basis for confidence in future predictions. As a result, PMIP has contributed significantly to the last two IPCC assessments.

In the last 10 years, climate models have moved from atmosphere-only to coupled ocean-atmosphere models and ocean-atmosphere-vegetation models. Models that include the coupling between the physical climate and biogeochemical cycles, such as the carbon cycle, have also been developed. These couplings, and the corresponding feedbacks, shape the response of the climate system to external variations. They are required to enable understanding of how climate has evolved through time and how it will evolve in the future in response to human activities. The second phase of PMIP (PMIP2) was launched in 2002 and addresses the role of the different feedbacks using these coupled models (Harrison et al., 2002; Crucifix et al., 2005).

All the information to run a PMIP2 simulation is available on the PMIP2 website (http://pmip2.Isce.ipsl.fr/; see Braconnot et al., 2007 for an overview). Model results are stored in a common database hosted at LSCE on raid disks and the data is distributed through a Linux file server. Guidelines, file format convention, variable names and structures, and utilities follow the requirements of the WCRP CMIP3 multi-model dataset. Participation in PMIP analyses is an open process. About 80 subprojects are now registered and most of them have already produced publications in high-level international journals (see, e.g., Fig. 1, and Otto-Bliesner and Brady, p. 18-20 this issue). Several data syntheses have also been released through the website, as well as a subset of maps showing 
a)

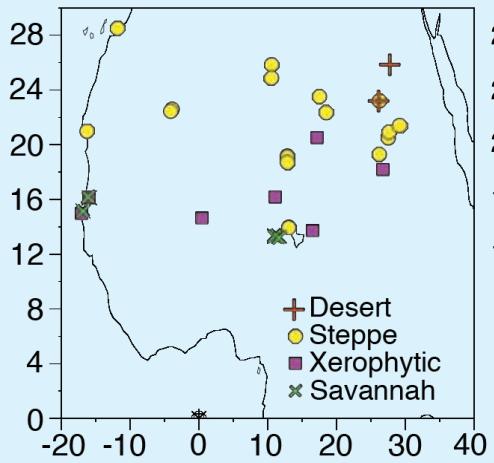

b)

$28^{\circ} \mathrm{N}$

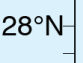

$24^{\circ} \mathrm{N}$

$20^{\circ} \mathrm{N}$

$16^{\circ} \mathrm{N}-$

$12^{\circ} \mathrm{N}-$

$8^{\circ} \mathrm{N}-$
$4^{\circ} \mathrm{N}-$
$0^{\circ}$
늋듀

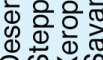

$\stackrel{\square}{\oplus} \stackrel{\oplus}{x}$

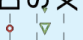

c)

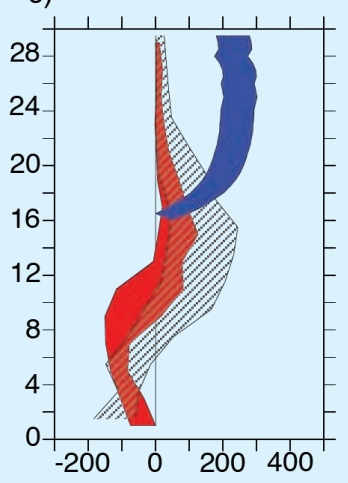

d)

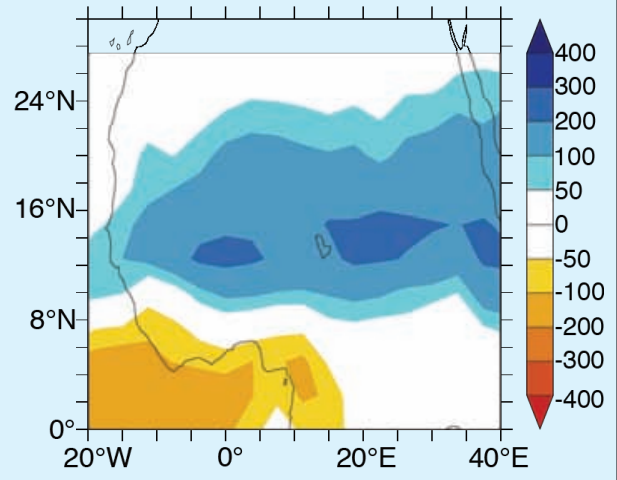

Figure 1: Biome and precipitation changes in Africa for the mid-Holocene. a) Biome distribution during the mid-Holocene. b) Zonal mean biome distribution for mid-Holocene (6kyr) and pre-industrial (Okyr) periods, and c) change in annual mean precipitation ( $\mathrm{mm} / \mathrm{yr}$ ) as simulated by the PMIP1 atmosphere alone models (red) and the PMIP2 coupled ocean-atmosphere models (black dashed). The model envelope is the range of precipitation covering $50 \%$ of the simulations around the median simulation. Blue band indicates the amount of precipitation that would be needed to replace modern desert by steppe. $\boldsymbol{d}$ ) Ensemble mean change of annual mean precipitation (mm/yr) estimated from PMIP2 coupled ocean-atmosphere simulations. These figures show that PMIP2 coupled simulations are in better agreement with data than PMIP1 atmosphere alone simulations but that they still fail to produce enough precipitation to sustain steppe as far as $23^{\circ} \mathrm{N}$, as suggested by pollen data. These figures are adapted from Jolly et al., 1998, Joussaume et al., 1999 and Braconnot et al., 2007.

results of the different models. Systematic model-data comparisons are a key element of the program. PMIP will continue to foster the development of improved methods of reconstructing climate parameters from paleo-observations, and of rigorous statistical approaches for comparing simulated and observed climates. This will ensure that these comparisons focus on appropriate variables and scales.

PMIP is now also interested in new periods, such as the early Holocene and the last glacial inception, and in new topics, such as "water-hosing experiments" (testing the sensitivity of the Atlantic meridional overturning to surface water flux forcing). State-of-the-art models can now be used to examine changes in short-term climate variability and in climate extremes, such as droughts or storms. PMIP has also started to promote the development of "forward models" for use in model evaluation and, increasingly, for coupling directly within a climate-model framework. These new challenges will require new data syntheses, including syntheses of high-resolution indicators.

PMIP has developed a new Science and Implementation Plan to help prepare for the next IPCC assessment. The plan (available from the PMIP2 website) is structured around four themes: 1 ) evaluation of Earth System models for 6 kyr BP and LGM, 2) interglacials and warm periods, 3) abrupt climate change, and 4) measures of model skill in simulating paleoclimate conditions. Details will be discussed at the next PMIP2 workshop (14-19 Sept 2008, Colorado, USA). This workshop will also showcase ongoing sub-projects and explore linkages between climate and environmental studies.

*World Climate Research Programme/Climate Variability and Predictability

\section{References}

Braconnot, P., et al., 2007: Results of PMIP2 Coupled Simulations of the Mid-Holocene and Last Glacial Maximum - Part 1: Experiments and Large-Scale Features, Climate of the Past, 3: 261-277.

Crucifix, M., Braconnot, P., Harrison, S.P. and Otto-Bliesner, B.L., 2005: Second Phase of Paleoclimate Modelling Intercomparison Project, EOS, 86: 264.

Harrison, S., Braconnot, P., Hewitt, C. and Stouffer, R.J., 2002: Fourth International Workshop of the Palaeoclimate Modelling Intercomparison Project (PMIP): Launching PMIP Phase I, EOS, 83 447-447.

Jolly, D., et al., 1998: Biome Reconstruction from Pollen and Plant Macrofossil Data for Africa and the Arabian Peninsula at 0 and $6 \mathrm{Ka}$, Journal of Biogeography, 25: 1007-1028.

Joussaume, S., et al., 1999: Monsoon Changes for 6000 Years Ago: Results of 18 Simulations from the Paleoclimate Modeling Intercomparison Project (PMIP), Geophysical Research Letters, 26 $859-862$

\section{An overview of some current CLIVAR modeling activities}

\section{Howard Cattle}

International CLIVAR Project Office, Southampton, UK; hyc@noc.soton.ac.uk

Modeling activities form a key component of CLIVAR, the World Climate Research Programme's Climate Variability and Predictability Project. From the global modeling perspective, these activities are carried out and coordinated through the joint WCRP/CLIVAR Working Group on Coupled Modelling (WGCM) and the CLIVAR Working Groups on Ocean Model Development (WGOMD) and on Seasonal to Interannual prediction (WGSIP). A key task for all of these groups is to maintain an oversight, and encourage developments in the component and coupled models needed for climate prediction (e.g., see Fig. 1). CLIVAR's regional monsoon and ocean basin panels also have modeling foci, often linked to results from CLIVAR-sponsored field programs such as the North American Monsoon Experiment (2004) or the current Tropical Atlantic Climate Experiment (2006-10), which has brought improved coverage of surface and subsurface data and dedicated process studies in the east-

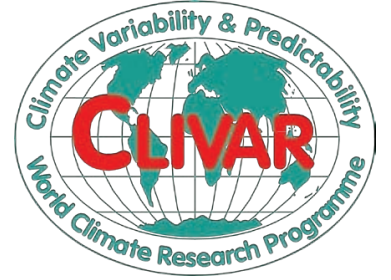

ern tropical Atlantic. In addition, CLIVAR's Global Synthesis and Observation Panel (GSOP) has a key activity to inter-compare the outputs of current global ocean synthesis efforts that use data assimilation of the historical dataset of ocean observations to produce consistent ocean analyses.

An important activity for the WGCM has been the coordination, under the Coupled Model Intercomparison project (CMIP-3), of the global coupled climate 